\title{
Study on the stable isotopes in surface waters of the Naqu River basin, Tibetan Plateau
}

\author{
Guoqiang Dong, $^{\mathrm{a}, \mathrm{b}}$, Baisha Weng ${ }^{\mathrm{b}}$, Tianling Qin ${ }^{\mathrm{b}}$, Denghua Yan ${ }^{\mathrm{b}, *}$, Hao Wang ${ }^{\mathrm{b}}$, Boya Gong ${ }^{\mathrm{b}}$, \\ Wuxia $\mathrm{Bi}^{\mathrm{b}, \mathrm{c}}$, Jianwei Wang ${ }^{\mathrm{b}}$ \\ a College of Environmental Science and Engineering, Donghua University, Shanghai 201620 China \\ b State Key Laboratory of Simulation and Regulation of Water Cycle in River Basin, China Institute of \\ Water Resources and Hydropower Research, Beijing 100038 China \\ c College of Hydrology and Water Resources, Hohai University, Nanjing 210098 China
}

*Corresponding author, e-mail: 2327139543@qq.com

Received 30 Jan 2018

Accepted 3 Nov 2018

\begin{abstract}
To enhance our understanding of the regional hydroclimate in the Central Tibetan Plateau, different types of water samples were collected across the Naqu River basin in the summer (July, August) and winter (January, December) of 2017 for isotopic analysis. With Cuona Lake as the demarcation point, the $\delta^{18} \mathrm{O}$ values of the river water increased initially and then decreased from upstream to downstream along the river's mainstream. In the Naqu River system, a general decrease of $\delta^{18} \mathrm{O}$ values in the trunk stream of the lower reaches (from the head of Cuona Lake) was revealed owing to the gradual dilution of increased isotopically-depleted tributary inflow. Lakes play an important role in regulating runoff and changes in the levels of stable isotopes in rivers or streams. Additionally, the decrease of $\delta^{18} \mathrm{O}$ is controlled by processes involved in the 'isotopic altitude effect'. Larger contributions of winter precipitation in surface runoff at higher elevations would produce higher deuterium excess in stream water. On the regional scale, with Cuona Lake as the demarcation point, one of the clearest findings was that the river/stream's deuterium excess values decreased first and then increased from the south to the north in the summer; but there was a positive linear increase in the winter. From geographical and climatological perspectives, the changes of deuterium excess could result from increasing effects of summertime, and the generation of continental/local recycled and monsoonal water vapor in the surface runoff northward. The study area is at the critical transition between the Indian monsoon system in the South and the Northern belt of the westerlies, as revealed by the intermediate deuterium excess values.
\end{abstract}

KEYWORDS: $\delta^{18} \mathrm{O}$ and $\delta \mathrm{D}$, hydrological cycle, water vapor sources, isotope-altitude relationship

\section{INTRODUCTION}

The Tibetan Plateau (TP) is often called the 'Third Pole' or the 'Water Tower of Asia' and is the source of many large Asian rivers, such as the Yangtze, Yellow, Lancang and Nujiang rivers ${ }^{1}$. Hydrological changes on the TP are critical to the security of freshwater resources in these rivers. As the only mid-latitude permafrost region, the TP is considered more sensitive to climatic warming than higher latitude Arctic regions ${ }^{2}$.

At present, the integrated application of isotopes and hydrochemical tracers has become an effective method for studying complex hydrological processes of multiple spatio-temporal scales ${ }^{3}$. The application of water stable isotopes $\left(\delta^{18} \mathrm{O}\right.$ and $\left.\delta \mathrm{D}\right)$ is progressively valuable as natural tracers of the hydrologic cycle in remote regions. Meanwhile, these stable isotopes are important for character- izing hydrological and ecological patterns and processes ${ }^{4}$. Because of fractionation driven by various hydrological and ecological processes, the composition of stable isotopes in environmental waters has changed $^{5}$. At the forefront of isotopic hydrology research, much emphasis has been placed on spatiotemporal variability of water isotopes in the Indus ${ }^{6}$ and the Ganges headwaters ${ }^{7}$ to determine surface runoff generation, moisture sources, and controls of environment and geography on precipitation. Yang et al found close hydrological relationships between rivers, thermokarst lakes and degrading permafrost in the Beiliuhe River Basin of the TP by using stable water isotopes ${ }^{8}$. By investigating the temporal and spatial variations of $\delta^{18} \mathrm{O}, \delta \mathrm{D}$ and deuterium excess (d-excess) values of river water and their relationships with climatic and geographic parameters, and by inverse trajectory analysis of water vapor sources, 
the effects of altitude and climatic parameters on the temporal and spatial variations of river water isotope values were clarified ${ }^{9}$. The main hydrological processes along the river were determined and the isotope response to flow variation was evaluated ${ }^{10}$.

In contrast, there were only few studies reported in the Nujiang River headwater region with stable isotopic tracers even though the region is geographically significant in hydrology, regional geology and climatology. To date, the systematic changes of stable isotopes in surface waters and precipitation in the Himalayas and on the TP have been specifically s tudied to d educe the transport range of Indian summer monsoon water vapor flux ${ }^{11}$. Data from the Himalayan front showed an obvious reverse correlation with altitude, and its lapse rate $\left(0.29 \% / 100 \mathrm{~m}\right.$ for $\left.\delta^{18} \mathrm{O}\right)$ was nearly equal to the global calibration of $0.28 \% 0 / 100 \mathrm{~m}^{12}$. In this research, a variety of water samples (such as those from river, stream, lake and reservoir waters) were collected in the Nujiang River headstream region (Naqu River basin) in January, July, August and December 2017. The results of this seasonal stable isotope hydrology study were used to determine: (1) the patterns of isotopic variation in these waters and the corresponding dominations, and (2) the hydrological processes upstream of the Nujiang River and the regional water vapor sources. Isotopic data of stream/river waters in this area were collected to propose a baseline of isotopic systematics with seasonal variations of water vapor sources and isotopealtitude correlations of stream/river waters.

\section{GEOGRAPHY AND CLIMATE}

The Nujiang River flows $f$ rom $t$ he $c$ entral TP (Fig. 1a), extending $2000 \mathrm{~km}$ and covering a watershed area of $137800 \mathrm{~km}^{2}$ in China. The headstreams of the Naqu River are located in the hinterland of the TP and are situated between the Tanggula Mountains to the north and the Nyenchen Tanglha Mountains to the south (Fig. 1a). The Tanggula Mountains, which range from east to west along the latitude of $32-33^{\circ} \mathrm{N}$, making the study site a transitional zone in the precipitation system between the north and south of the $\mathrm{TP}^{13}$. This river finally derives from the glacier on the southern slope of the Tanggula Mountains (Fig. 1a), which has a range of altitude between 5000 and $5800 \mathrm{~m}$ above sea level (a.s.l.).

This study was conducted in the Naqu River basin, which is the source of the Nujiang River, located in the hinterland of the TP (Fig. 1a). The area of the total watershed covers $16967.4 \mathrm{~km}^{2}$, and the elevation of the watershed ranges from 4140 to $5897 \mathrm{~m}$ a.s.l. (Fig. 1a). The upper Naqu River flows approximately to Amdo City (Fig. 1b), and the tributaries primarily include the Lariqu, Sangqu, Chengqu, Mugequ, Gongqu and Luoqu. One large outflow lake, Cuona Lake, is located immediately north of the Naqu River (Fig. 1b). The mean elevation of this region is more than $4500 \mathrm{~m}$ a.s.l. Since the Himalayas obstruct water vapor transport from the Indian Ocean to the south, and the Karakoram and Pamir mountains obstruct water vapor transport from the Mediterranean and the Atlantic Ocean to the west, a semi-arid climate is mainly found in this region.

The study area experience cold and dry continental alpine climate with a mean annual air temperature of $-0.6^{\circ} \mathrm{C}$ and annual mean precipitation of $477.8 \mathrm{~mm}$. The average summer and winter temperatures are $9.7^{\circ} \mathrm{C}$ and $-10.7^{\circ} \mathrm{C}$, respectively. The peak temperatures occur in July and August, and the monthly mean air temperature is above $0{ }^{\circ} \mathrm{C}$ from May-September. Precipitation events that occur from June-September account for $80 \%$ of the total annual precipitation, and the highest precipitation occurs in July and August. During the freezing season from November to April, the total precipitation is normally less than $5 \mathrm{~mm}$, and the river channel usually contains no liquid water for sampling.

\section{SAMPLING AND ANALYTICAL METHODS}

A variety of water samples were collected during a synoptic investigation in January, July, August and December 2017 across the headwater region of the Nujiang River (Naqu River basin). Three lake water samples were obtained at Cuona Lake (Fig. 1b). We collected 83 river water samples from the Naqu River and its tributaries (river/stream) from Amdo to Nagqu along National Roads 109 and 317 , conducting a roughly north-to-south vertical section (covering approximately 3 degrees of latitude; Fig. 1b).

All water samples were collected in $50 \mathrm{ml}$ highdensity polyethylene bottles and stored at cool temperatures until analysis. The $\delta^{18} \mathrm{O}$ and $\delta \mathrm{D}$ values in all water samples were determined by cavity ring down laser spectroscopy (CRDS) using an L2130-i Picarro water isotope analyzer. For $\delta^{18} \mathrm{O}$ and $\delta \mathrm{D}$ measurements, the analytical precision was $\pm 0.025 \%$ and $\pm 0.1 \%$, respectively. The isotopic values of water were reported as per mil $(\%)$ unit relative to the standard Vienna Standard Mean 

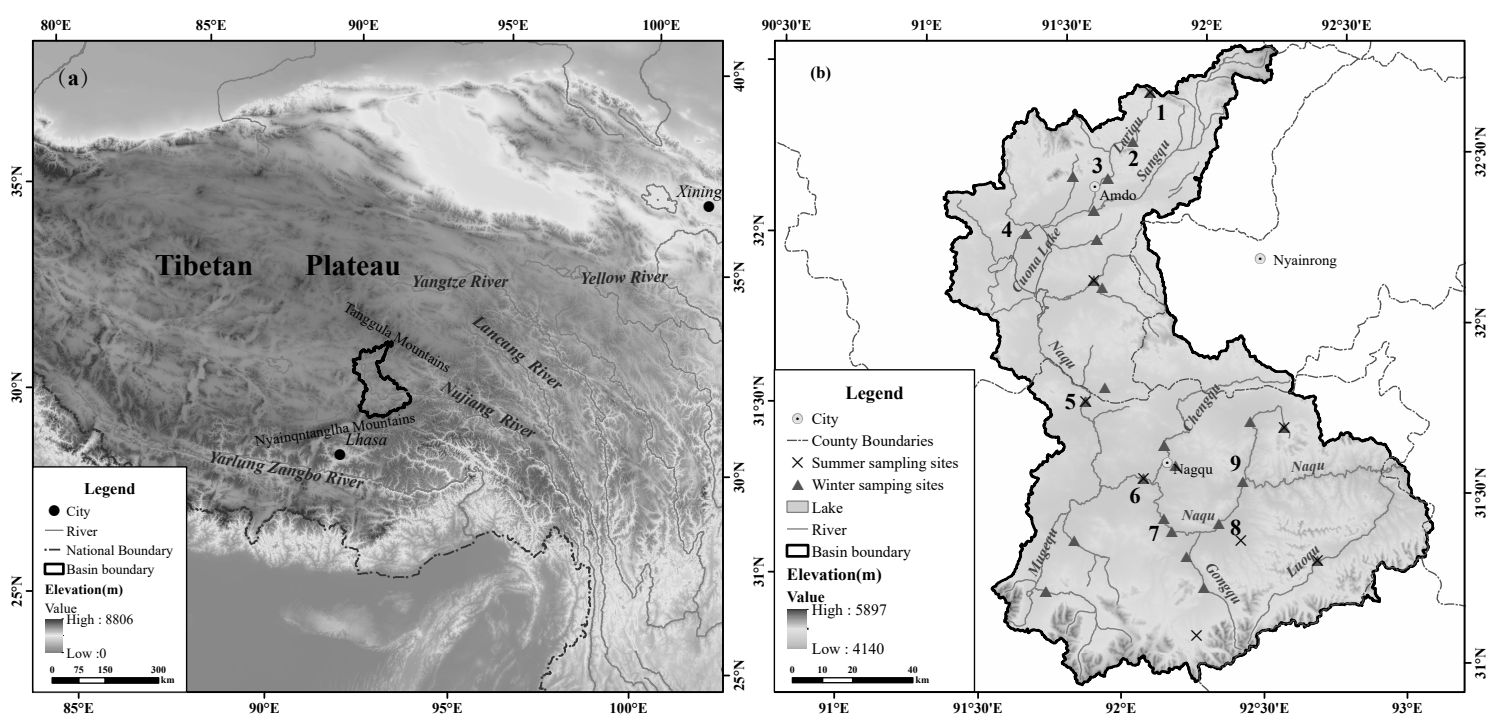

Fig. 1 (a) Geographical location of the Naqu River basin. (b) Map of sample locations of different waters from the Naqu River basin.

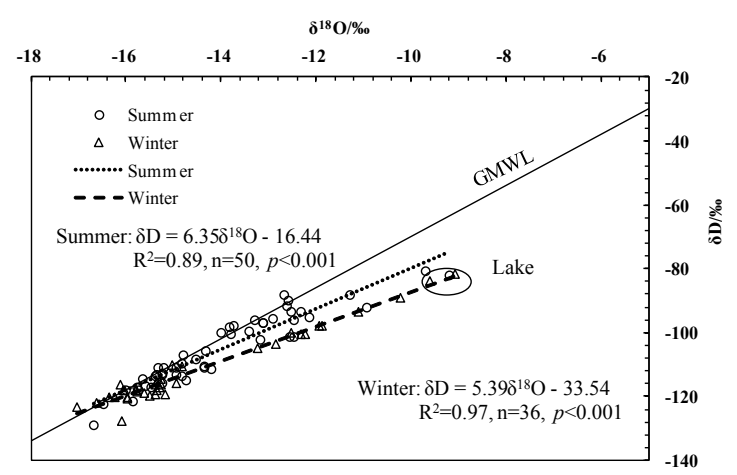

Fig. $2 \delta^{18} \mathrm{O}$ and $\delta \mathrm{D}$ results for all waters in relation to the GMWL. The local water lines (summer and winter) were developed using isotopic data of lake, reservoir, river, and stream samples.

Ocean Water (VSMOW) ${ }^{5}$,

$$
\delta^{\mathrm{n}} \mathrm{A}(\% 0)=\frac{R_{\text {Sample }}-R_{\text {VSMOW }}}{R_{\text {VSMOW }}} \times 1000
$$

where $n$ is the atomic mass of the heavy isotope of element A, $R_{\text {Sample }}$ the ratio of heavy to light isotope $\left({ }^{2} \mathrm{H} /{ }^{1} \mathrm{H}\right.$ or $\left.{ }^{18} \mathrm{O} /{ }^{16} \mathrm{O}\right)$ in a sample, and $R_{\text {VSMOw }}$ the ratio of heavy to light isotope in international isotopic measurement standard VSMOW.

All the measured isotopic values of samples were plotted, as shown in Fig. 2. The linear correlation between $\delta \mathrm{D}$ and $\delta^{18} \mathrm{O}$ values of global precipitation was described by $\delta \mathrm{D}=8 \delta^{18} \mathrm{O}+10$ or $\delta \mathrm{D}$
$=8.17 \delta^{18} \mathrm{O}+10.35$ (see Refs. 14,15 ). The global meteoric water line (GMWL) is a valuable reference line for comprehending the spatial variability in the evaporation effect and precipitation isotopes based on the deviation from the line ${ }^{16}$. Surface waters and precipitation are commonly near the GMWL, normally with a lower slope owing to surface evaporation and subcloud evaporation of precipitation.

The deuterium excess, $(\mathrm{d}$-excess $=\delta \mathrm{D}$ $\left.-8 \delta^{18} \mathrm{O}\right){ }^{17}$ of precipitation with a global mean of $10 \%$, reveals kinetic isotopic fractionation in the moisture source region (as a function of temperature, relative humidity and wind speed) and interaction or mixing of moisture along the water vapor trajectory ${ }^{18}$. The d-excess decreases when subcloud/surface evaporation occurs and increases when moisture is recycled ${ }^{19}$, with precipitation originating from continental/local evaporation and recycled water vapor having high d-excess values across the TP and the Himalayas. Because of the high relative humidity over the water vapor source area (e.g., Bay of Bengal), the weighted-mean d-excess of monsoon precipitation in the summer is $4-6 \%$ on the northern slopes of the central Himalayas and in the southern $\mathrm{TP}^{20}$.

\section{RESULTS}

There was a range in $\delta^{18} \mathrm{O}$ and $\delta \mathrm{D}$ values in the water samples (including lake, reservoir, river and stream) across the Naqu River basin. For $\delta^{18} \mathrm{O}$, the values varied from $-17 \%$ to $-9 \%$ with an 
average of $-14.2 \%$. For $\delta \mathrm{D}$, the values varied from $-129 \%$ to $-81 \%$ with an average of $-107.8 \%$. The d-excess ranged from $-9 \%$ to $13 \%$ with an average of 5.6\%. The value of mean d-excess was remarkably lower than that of the global mean. Processes in moisture transport/rainfall (e.g., mixture of different summertime moisture) and generation of surface runoff (e.g., mixture of various seasonal precipitation) may cause confusion about the original source of the moisture.

Lake water was the most isotopically abundant with an average of $-9.3 \%$ for $\delta^{18} \mathrm{O}$, and water from sampling site 1 , collected in January from the Lariqu River in the most northern part of the study area, was the most isotopically depleted with $\delta^{18} \mathrm{O}$ of $-17 \%$. This may be due to the fact that the collected water samples were located at the source of the river, i.e., from mountain springs. Since these sampling points were relatively high in elevation and samples were taken during low winter temperatures, the stable isotopes in the river had hardly experienced evaporation fractionation. Three lake water samples deviated significantly from the GMWL in Fig. 2, whereas most of the other waters obtained from the Naqu River basin fell below the GMWL on the right-down side, showing the significance of evaporation due to the long-term residence time of surface water.

\section{DISCUSSION}

\section{Stable isotopes in surface waters}

Water in rivers and streams may come from precipitation and/or groundwater, depending on the amount of recent precipitation and the size of the basin ${ }^{21}$. As shown in Fig. 2, the $\delta^{18} \mathrm{O}$ and $\delta \mathrm{D}$ of river waters in summer yielded a surface water line (SWL) of $\delta \mathrm{D}=6.35 \delta^{18} \mathrm{O}-16.44\left(\mathrm{R}^{2}=0.89\right.$, $\mathrm{n}=50$ ), which is close to the winter one of $\delta \mathrm{D}$ $=5.39 \delta^{18} \mathrm{O}-33.54\left(\mathrm{R}^{2}=0.97, \mathrm{n}=36\right)$. All the summer and winter data points defined a SWL of $\delta \mathrm{D}=5.94 \delta^{18} \mathrm{O}-23.54\left(\mathrm{R}^{2}=0.90, \mathrm{n}=86\right)$ and its slope is close to that for the Naqu River basin ${ }^{22}$ of $\delta \mathrm{D}=5.70 \delta^{18} \mathrm{O}-30.12$.

The slopes and intercepts of these SWLs are lower than those of the GMWL, which suggested that stable isotopes in the river experienced a strong evaporation fractionation effect. At the same time, the slope and intercept of the surface water line in the winter are lower than those in the summer. This shows that the stable isotopes in the river water in the winter were more enriched than those in the summer. Being different from precipitation, surface waters may undergo multiple processes to change the relationship between the $\delta^{18} \mathrm{O}$ and $\delta \mathrm{D}$ (e.g., post-depositional snow processes and evaporation). For instance, snowmelt has not been significantly affected but refreezing lead to a lower slope ${ }^{23}$. Therefore, the gentle slopes might be due to snowmelt or refreezing. Evaporation can also affect the slope because a lower slope can be found in residuary waters ${ }^{24}$. As shown in Fig. 2, samples were normally divided into near to or below the GMWL. The combination of water samples produced gentle $\delta^{18} \mathrm{O}-\delta \mathrm{D}$ slopes, which were on the lower-right side (below the GMWL, with lower $d$-excess and $\delta^{18} \mathrm{O}$ ). Furthermore, this result confirmed the negative correlations between $\delta^{18} \mathrm{O}$ and d-excess, while the slopes were $-1.65\left(\mathrm{R}^{2}=0.36, \mathrm{n}=50, p<0.001\right)$ in the summer and $-2.61\left(\mathrm{R}^{2}=0.87, \mathrm{n}=36, p<0.001\right)$ in the winter. Owing to the fact that surface water eventually comprises of diverse mixtures of precipitation in diverse seasons during runoff formation, river waters with relatively low $\delta^{18} \mathrm{O}$ and d-excess most likely corresponded to relatively greater effects of summer monsoon precipitation, whereas those with greater d-excess and $\delta^{18} \mathrm{O}$ most likely corresponded to larger contributions of winter precipitation.

At the identical sampling site on the main stream, the winter $\delta^{18} \mathrm{O}$ values were consistently greater than those in the summer (e.g., Nagqu, $-11.9 \%,-12.0 \%$ in the winter and $-12.3 \%$, $-14.2 \%$ in the summer). This difference might be because the stable isotopes in precipitation of the basin observed are primarily dominated by diverse seasonal circulation models. When dominated by the Indian Ocean monsoon in the summer, the isotopic values are lower, with frequent fluctuations; particularly in the spring or winter when the continental air masses dominate the basin, which usually lead to greater values ${ }^{25}$.

The d-excess values in precipitation present a clear transition at Nagqu because of the location in the central TP. In the summer, the low d-excess values in precipitation are generally due to southern water vapor transport, which is mainly from the hot and humid Indian Ocean. In the winter, d-excess values in precipitation are generally higher because this region is controlled by westerlies and a northern air mass, which is cool and dry ${ }^{26}$. A value of $10 \%$ for d-excess can distinguish between evaporation under humid (below 10\%0) and dry (above 10\%0) climatic conditions ${ }^{13}$. The similar stream water $\mathrm{d}$ excess in the winter $(4.2 \pm 5.9 \%)$ and the summer $(6.7 \pm 4.6 \%)$ was one of the most obvious findings for the Naqu River basin. Although these values are 


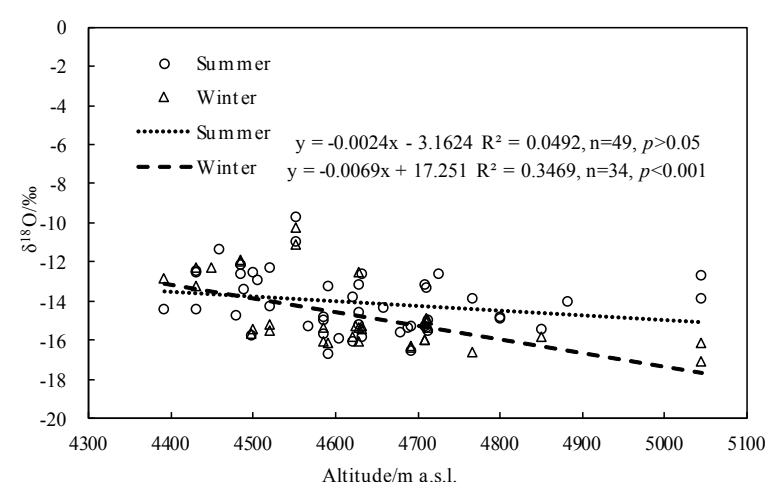

Fig. 3 Catchment elevation vs river water $\delta^{18} \mathrm{O}$ in the summer and the winter for the Naqu River basin.

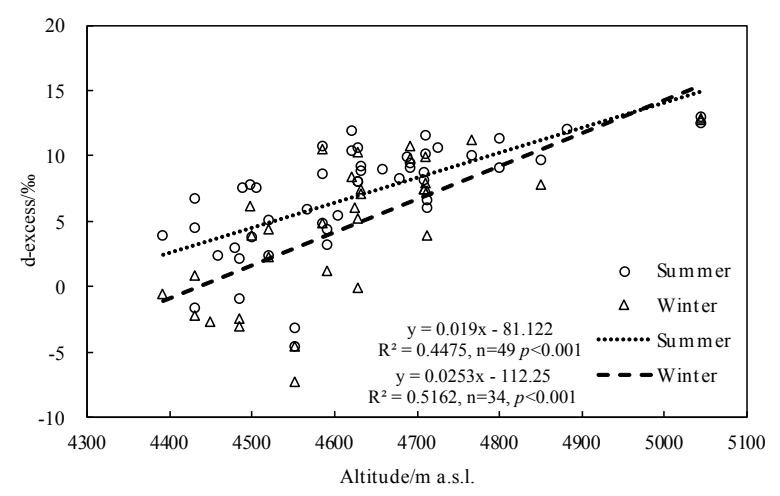

Fig. 4 Catchment elevation vs d-excess of stream waters collected in the summer and the winter from the Naqu River basin.

lower than the global mean value of $10 \%$, they are similar to those from the north of the Himalayas to the south of the Tanggula Mountains $(5.3 \%)^{25}$, which are relevant to the westward transport of water vapor and low temperatures during precipitation. In the central TP, rivers and streams are primarily composed of snowmelt and precipitation in the summer, and base flow and precipitation in the winter. High d-excess of stream water most likely represented the isotopic characteristic of precipitation in the winter and snowmelt in the summer. The medium d-excess values of river waters in summer signified the mixture between glacier melt and monsoonal rainfall.

\section{Altitudinal variability in $\delta^{18} \mathrm{O}$ and d-excess}

When an air mass is topographically uplifted and adiabatically cooled, a negative correlation is observed between precipitation $\delta^{18} \mathrm{O} / \delta \mathrm{D}$ and elevation. The vertical lapse rates of $\delta^{18} \mathrm{O}$ in precipitation/surface water reveal a global calibration of
$0.28 \% / 100 \mathrm{~m}^{12}$. Previous studies based on altitude data of samples showed a vertical lapse rate of $0.26 \% / 100 \mathrm{~m}$ in the central $\mathrm{TP}^{25}$. From Fig. 3, the expected negative correlations were shown between $\delta^{18} \mathrm{O}$ and elevation as their vertical lapse rates were $0.24 \% / 100 \mathrm{~m}\left(\mathrm{R}^{2}=0.05, \mathrm{n}=49, p<0.05\right)$ in the summer and $0.69 \% / 100 \mathrm{~m}\left(\mathrm{R}^{2}=0.35, \mathrm{n}=\right.$ $34, p<0.001)$ in the winter. The total lapse rate was $0.44 \$ / 100 \mathrm{~m}\left(\mathrm{R}^{2}=0.16, \mathrm{n}=83, p<0.001\right)$. Therefore, the vertical lapse rates of stream water $\delta^{18} \mathrm{O}$ in the Naqu River basin $(0.24-0.69 \% / 100 \mathrm{~m})$ are higher than the global mean value.

The stable isotopes of river/stream waters are affected by hydrological and climatic conditions in the upper reaches of the river basin. We studied the relationship between $\delta^{18} \mathrm{O}$ and watershed elevation of water samples to assess the topographic impacts, and a significant correlation was observed for the waters in the winter but the correlation coefficient was not large. The values of $\delta^{18} \mathrm{O}$ decreased gradually with the increase of elevation in the winter. This result suggested that the $\delta^{18} \mathrm{O}$ pattern in Fig. 3 was dominated by processes of the isotopic altitude effect in the winter but it was not the most important factor. Due to the altitude effect to precipitation $\delta^{18} \mathrm{O}$, greater effects of winter precipitation in the formation of surface runoff at lower altitudes would increase extra isotopic abundance in stream waters. Such a phenomenon is obviously more significant for high-elevation regions ( $>4000 \mathrm{~m}$ a.s.l.) based on their larger $\delta^{18} \mathrm{O}$ lapse rates ${ }^{27}$.

For $\delta^{18} \mathrm{O}$, the correlation was poor with altitude in the summer. The following reasons might explain the poor correlation. Obvious differences occurred in the recharge types of rivers in different areas of the basin. The impact of precipitation may also be one of the reasons. Although precipitation recharge is the primary factor during the monsoon season, differences occurred in different reaches of the river. Sites in the lower reaches of the river were affected not only by local precipitation but also by precipitation from the upper reaches.

At gradually colder temperatures of condensation, Rayleigh fractionation of an air mass leads to dexcess in precipitation to increase with altitude ${ }^{21,28}$. Decrease in distance between the cloud base and ground at high altitudes may also increase d-excess in precipitation because of the decreased subcloud evaporation of raindrops ${ }^{29}$. The increase of dexcess in precipitation/surface water with altitude was proven on the windward slope of the Andes ${ }^{28}$, in Antarctica ${ }^{30}$, on the Himalayan front ${ }^{6}$ and in the central TP (Nagqu to Tanggula Mountains) ${ }^{25}$. It 


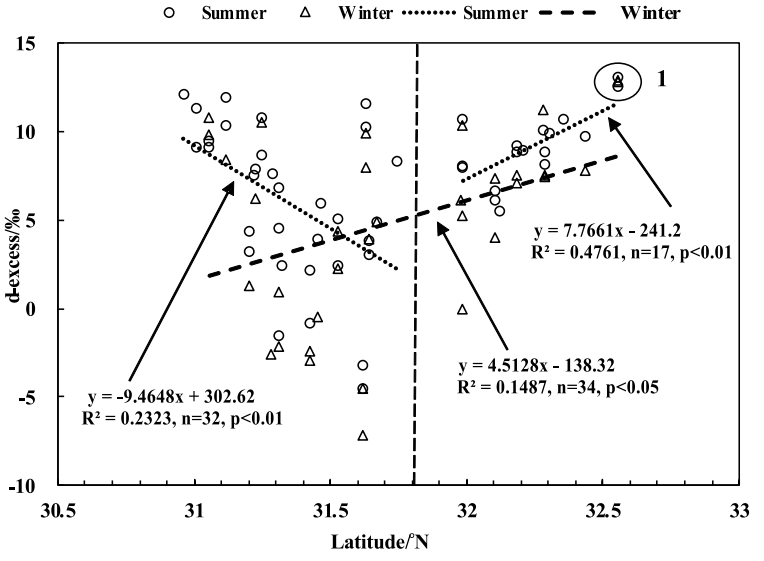

Fig. 5 Catchment latitude vs d-excess of stream waters collected in the summer and the winter from the Naqu River basin.

also demonstrated positive correlations between dexcess and catchment altitude, either in the summer or in the winter for river waters of the central TP (Fig. 4). Their vertical lapse rates were $1.90 \% 0 / 100 \mathrm{~m}\left(\mathrm{R}^{2}=0.45, \mathrm{n}=49, p<0.001\right)$ in the summer and $2.53 \%$ o $/ 100 \mathrm{~m}\left(\mathrm{R}^{2}=0.52, \mathrm{n}=34\right.$, $p<0.001)$ in the winter. The total lapse rate was $2.18 \%$ o $100 \mathrm{~m}\left(\mathrm{R}^{2}=0.45, \mathrm{n}=83, p<0.001\right)$. This phenomenon indicates that post-precipitation played a dominant role, with the increasing role of summer and winter precipitation in the formation of surface runoff with altitude. Larger contributions of summer and winter precipitation in the surface runoff at higher elevations would produce higher stream water d-excess.

\section{North-south variability in d-excess and implications for water vapor sources}

Tian et $\mathrm{al}^{31}$ discovered an obvious division between monsoon precipitation and non-monsoon precipitation on the TP because of the varieties of $\delta^{18} \mathrm{O}$ in precipitation in the summer and the winter. The division was coincident with the Tanggula Mountains and showed the northerly extension of the Indian Ocean monsoon. The area under investigation was located in the central TP, south of the Tanggula Mountains, and the d-excess values in precipitation presented a pronounced change at Nagqu due to its central location ${ }^{26}$.

The water vapor of the TP originates from three sources: the westerlies, Indian monsoon and local recycling. There are relative proportions of each change on spatial and temporal scales. Previous research indicates that the TP can generally be di- vided into three regions: Indian monsoon (southern $\mathrm{TP}$ ), westerlies (northern TP) and the transitional zone in between ${ }^{11}$. The monsoonal water vapor is dominant in the central TP in summer, however the westerlies are more crucial in the north and west, leading to systematic variability of latitude and longitude in water stable isotopes ${ }^{32}$. These sources bring into correspondence with the isotopic patterns in the northern TP. Therefore, Tian et $\mathrm{al}^{33}$ postulated that this area is dominated by the westerlies and that the monsoonal water vapor can arrive at the northern TP only by violent atmospheric activities.

Yao et $\mathrm{al}^{34}$ noted that when the marine air mass reaches the northern TP, the $\delta^{18} \mathrm{O}$ value of the moisture is small due to precipitation fractionation processes. Thus, when precipitation is formed by an oceanic air mass, the $\delta^{18} \mathrm{O}$ value of the precipitation samples is definitely small. However, the precipitated moisture primarily originates from local evaporation in the interior of the plateau before the ocean air mass reaches the TP. Rivers and lakes are the main sources of local evaporation on the plateau $^{35}$. In the northward of the TP, the fact is that southwest winds also carries moisture of the Indian Ocean from the Bay of Bengal through the Bulamaputela River valley-Yarlungzangbo River valley from the south of the TP to the interior of the plateau $^{36}$.

The spatial variability of water stable isotopes at large scales usually provides sufficient evidence for regional variations in water vapor sources ${ }^{21}$. As shown in Fig. 5, trends of south-north variation of dexcess were apparent. The d-excess decreased $\left(\mathrm{R}^{2}=\right.$ $0.23, \mathrm{n}=32, p<0.01$ ) farther to the north near $31.8^{\circ} \mathrm{N}$ latitude but progressively increased $\left(\mathrm{R}^{2}=\right.$ $0.48, \mathrm{n}=17, p<0.01$ ) farther to the north in the summer, with the changes caused by regional variations in moisture sources ${ }^{37}$. It demonstrated positive correlations between d-excess and catchment latitude in the winter $\left(\mathrm{R}^{2}=0.15, \mathrm{n}=34, p<\right.$ 0.05 ) for river waters from the south to the north. Therefore, the Naqu River basin is probably at a critical geographical transition between the south and the north.

The d-excess usually changes gradually in two parts at the division near Cuona Lake in the summer, and the evaporation of lake water is one of the sources of water vapor, which is greatly reduced in the winter. These can be explained by the increasing contributions of summer-time continental/local recycled moisture and northward monsoonal moisture, although it is difficult to identify the ultimate 
source(s) at this present stage (i.e., local recycled, westerlies or north-derived). Therefore, the influence of lake water on the source of water vapor in the summer is greater than that in the winter. In the Himalayas and the southern TP, summer monsoon precipitation has d-excess values lower than $10 \%$ (with average values of 4-6\%0) due to the high humidity over the oceanic source region and convection along the trajectory ${ }^{27}$. If the weighted-average d-excess of winter precipitation at Lhasa $(15.2 \%$ ) represents the westerly value ${ }^{38}$, the d-excess values in the Naqu River basin (mean of 7.0\%, in the summer) were intermediate between the monsoon and westerly values. However, the extremely high d-excess values of the stream waters near Tanggula Mountains (Fig. 5, sampling site 1, $12.9 \%$ in January, $13.0 \%$ in July, $12.5 \%$ in August and $12.8 \%$ in December) probably indicate the predominance of the continental recycled moisture in that region. These data thus confirm the geographical transition of the Naqu River basin between the monsoon system in the south and the westerly one in the north.

\section{Hydrological processes along the Naqu River}

Some waters in the trunk stream and tributaries of the Naqu River system fall close the GMWL in Fig. 2. This result indicated that although the climate at the locations of the sampling site was semiarid, evaporation is not essential because of the rapid stream, owing to the steep altitude gradient and low temperatures ${ }^{36}$.

Most of these studies show that river $\delta^{18} \mathrm{O}$ is generally on the rise with distance from their river source, which is due to the cumulative effect of evaporation as water flows downstream and the altitude effect of precipitation isotopes in the basin ${ }^{10}$. As shown in Fig. 6, on the basis of the distributions of the sampling sites and the isotopic values along the river's mainstream, the $\delta^{18} \mathrm{O}$ of the river water increased initially and then decreased from upstream to downstream, with the highest $\delta^{18} \mathrm{O}$ values observed in Cuona Lake (sampling site 4). This result was probably caused by slight evaporation from the open water because some flow-through lakes occur in the basin (the largest one is Cuona Lake, Fig. 1b) and then obtain relatively enriched precipitation in the southern part of the basin. Moreover, the $\delta^{18} \mathrm{O}$ values in the trunk stream were relatively greater than those in the tributaries at the same elevation.

There was a large flow-through lake (Cuona Lake, $23 \mathrm{~km}$ long and $8 \mathrm{~km}$ wide) in the main channel. Although the stream influx of this lake showed more depleted signals, the outflow $\delta^{18} \mathrm{O}$ (sampling site 5, $-10.3 \%$ in January, $-9.7 \%$ in July, $-10.9 \%$ in August and $-11.1 \%$ in December) were obviously greater than those upstream (sampling site $3,-16.0 \%$ in January, $-13.1 \%$ in July, $-15.2 \%$ in August and $-16.0 \%$ in December), presumably because water passes very slowly through this lake and the stream influx exerts minimal isotopic influence on main flows. Downstream from this flowthrough lake, dilution from tributary inflow is obviously the primary reason of the gradual depletion in the isotopes of trunk stream. In the lower reaches of the lake, it exhibits a characteristic downstream decrease in $\delta^{18} \mathrm{O}$, which is opposite to the anticipated pattern owing to the altitude effect on precipitation isotopes and the cumulative effect of evaporation as water flows downstream. For instance, nearly all the $\delta^{18} \mathrm{O}$ values in the stream influx are lower than those in the main flow at the same distance. Therefore, isotope dilution in tributary inflow was the major hydrological process along the downstream Naqu River. From the spatial variation, due to the influence of basin elevation, the scale of the catchment area and the lake water, the isotopic compositions and fluctuation amplitudes upstream are lower than those downstream ${ }^{22}$. Additionally, Cuona Lake plays an important role in regulating runoff and changes of stable isotopes in the river or stream. These suggest that the increase around $32^{\circ} \mathrm{N}$ may be due to the enhanced hydrological significance of lake because its abundance is highest near the same latitudes.

Most of the geographic and climatic regions, from the source to the continental basin scale, showed attenuation of isotope signals from precipitation to water flow, confirming the large amount of water storage and mixing of water during runoff generation ${ }^{39}$. It should be noted that because of the spatial extent of the sampling campaigns and associated logistical challenges, the temporal variability along the transect inevitably remains somewhat uncertain.

\section{CONCLUSIONS}

This paper states $\delta^{18} \mathrm{O}$ and $\delta \mathrm{D}$ data of waters in the Naqu River basin of the central TP. Along the river's mainstream, the $\delta^{18} \mathrm{O}$ of the river water increased initially and then decreased from upstream to downstream, and the highest $\delta^{18} \mathrm{O}$ values were observed in Cuona Lake. In the Naqu River system, a general decrease of $\delta^{18} \mathrm{O}$ in trunk stream of the lower reaches (from the head of the Cuona Lake) was revealed owing to the gradual dilution of more 

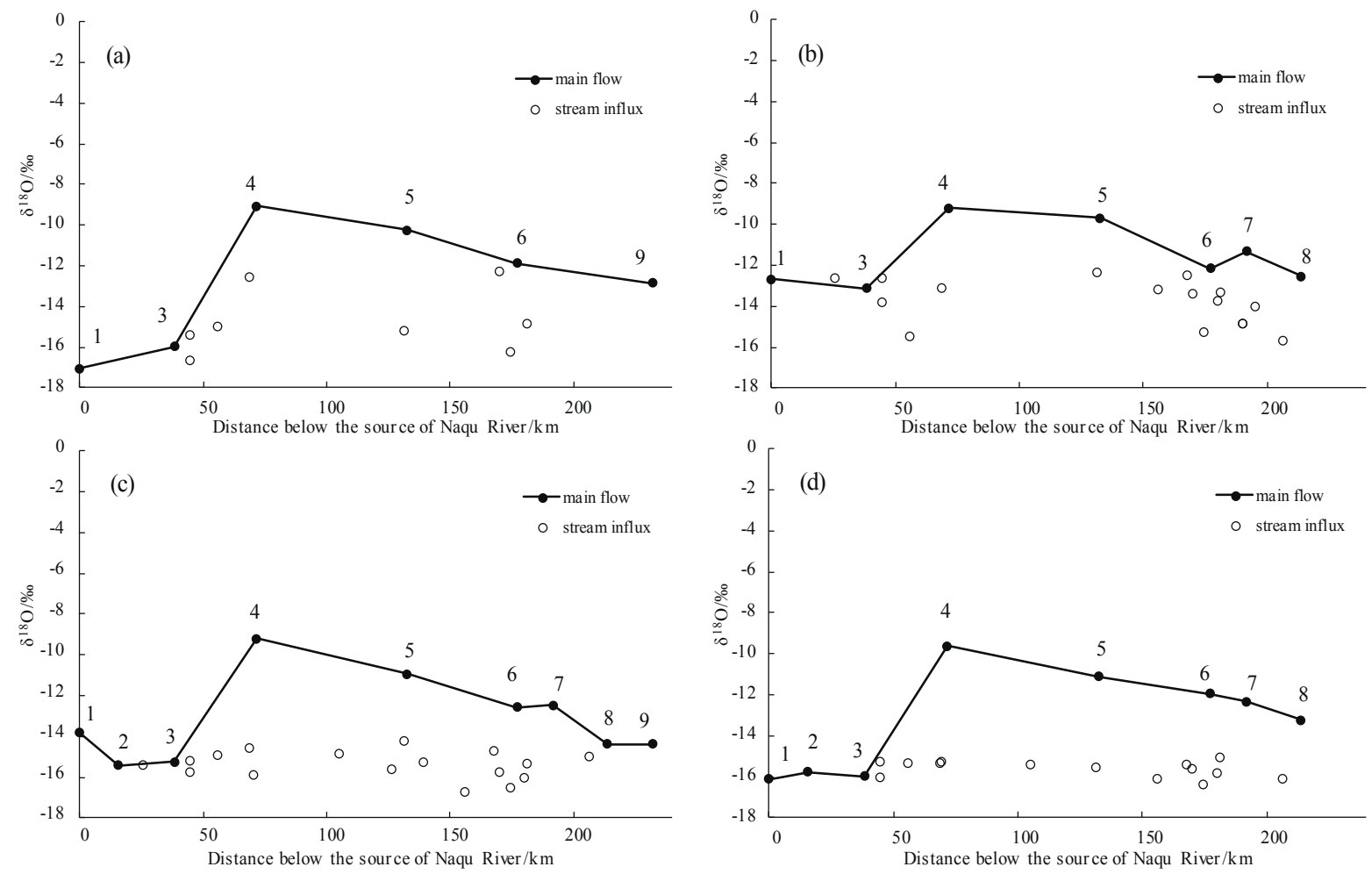

Fig. 6 Main flow and stream influx of $\delta^{18} \mathrm{O}$ vs. distance downstream from the source of the Naqu River; (a) January 2017, (b) July 2017, (c) August 2017, (d) December 2017.

isotopically depleted tributary inflow. Lakes play an important role in regulating runoff and changes of stable isotopes in the river or stream.

At the regional scale (with Cuona Lake as the demarcation point), the river/stream d-excess decreased first and then increased from south to north in the summer; but there was a positive linear increase in the winter. These may be due to increasing contributions of summer-time continental/local recycled moisture and monsoonal moisture northward. The processes of the 'isotopic altitude effect' controlled the $\delta^{18} \mathrm{O}$ pattern, but it is not the most important factor. Greater contributions of summer and winter precipitation in the formation of surface runoff at higher altitudes contributed to altitudinal increase in stream water d-excess and greater vertical lapse rates of stream water $\delta^{18} \mathrm{O}$. Data revealed that the Naqu River basin is at the transition between the westerly system in the north and the monsoon one in the south. Further investigations into long-term variation of isotopes in precipitation and surface water will improve interpretations of the hydroclimate in this region.

Acknowledgements: This study was supported by the
Major Research Plan of the National Natural Science Foundation of China (No. 91547209); the General Program of the National Natural Science Foundation of China (No. 41571037); the National Key Research and Development Project (No. 2016YFA0601503); the Open Research Foundation from State Key Laboratory of Simulation and Regulation of Water Cycle in River Basin (No. 2015ZY02); the Fundamental Research Funds for the Central Universities (No. CUSF-DH-D-2017101).

\section{REFERENCES}

1. Curio J, Scherer D (2016) Seasonality and spatial variability of dynamic precipitation controls on the Tibetan Plateau. Earth Syst Dynam 7, 767-82.

2. Song CL, Wang GX, Liu GS, Mao TX, Sun XY, Chen XP (2017) Stable isotope variations of precipitation and streamflow reveal the young water fraction of a permafrost watershed. Hydrol Process 31, 935-47.

3. Cui BL, Li XY (2015) Runoff processes in the Qinghai Lake Basin, Northeast Qinghai-Tibet Plateau, China: Insights from stable isotope and hydrochemistry. Quat Int 380-1, 123-32.

4. West AG, February EC, Bowen GJ (2014) Spatial analysis of hydrogen and oxygen stable isotopes ('isoscapes') in ground water and tap water across south Africa. J Geochem Explor 145, 213-22. 
5. Zhao SH, Hu HC, Tian FQ, Tie Q, Wang LX, Liu YL, Shi CX (2017) Divergence of stable isotopes in tap water across China. Sci Rep 7, 43653.

6. Karim A, Veizer J (2002) Water balance of the Indus River Basin and moisture source in the Karakoram and western Himalayas: Implications from hydrogen and oxygen isotopes in river water. $J$ Geophys Res Atmos 107, 9-12.

7. Lambs L (2000) Correlation of conductivity and stable isotope ${ }^{18} \mathrm{O}$ for the assessment of water origin in river system. Chem Geol 164, 161-70.

8. Yang YZ, Wu QB, Hou YD, Zhang ZQ, Zhan J, Gao SR, Jin HJ (2017) Unraveling of permafrost hydrological variabilities on Central Qinghai-Tibet Plateau using stable isotopic technique. Sci Total Environ 605-6, 199-210.

9. Ala-aho P, Soulsby C, Pokrovsky OS, Kirpotin SN, Karlsson J, Serikova S, Vorobyev SN, Manasypov RM, et al (2018) Using stable isotopes to assess surface water source dynamics and hydrological connectivity in a high-latitude wetland and permafrost influenced landscape. J Hydrol 556, 279-93.

10. Ren W, Yao TD, Xie SY (2018) Stable isotopic composition reveals the spatial and temporal dynamics of discharge in the large river of Yarlungzangbo in the Tibetan Plateau. Sci Total Environ 625, 373-81.

11. Yao TD, Masson-Delmotte V, Gao J, Yu WS, Yang XX, Risi C, Sturm C, Werner M, et al (2013) A review of climatic controls on $\delta^{18} \mathrm{O}$ in precipitation over the Tibetan Plateau: Observations and simulations. Rev Geophys 51, 525-48.

12. Rowley DB, Garzione CN (2007) Stable isotopebased paleoaltimetry. Annu Rev Earth Planet Sci $\mathbf{3 5}$ 463-508.

13. He SY, Richards K (2016) Stable isotopes in monsoon precipitation and water vapour in Nagqu, Tibet, and their implications for monsoon moisture. $J$ Hydrol 540, 615-22.

14. Craig H (1961) Isotopic variations in meteoric waters. Science 133, 1702-3.

15. Clark I, Fritz P (1997) Environmental Isotopes in Hydrogeology, CRC Press, New York.

16. Rozanski K, Araguás-Araguás L, Gonfiantini R (1993) Isotopic patterns in modern global precipitation. In: Swart PK, Lohmann KC, Mckenzie J, Savin S (eds) Climate Change in Continental Isotopic Records 78, AGU, Washington DC, pp 1-36.

17. Dansgaard W (1964) Stable isotopes in precipitation. Tellus 16, 436-68.

18. Araguás-Araguás L, Froehlich K, Rozanski K (2000) Deuterium and oxygen-18 isotope composition of precipitation and atmospheric moisture. Hydrol Process $14,1341-55$.

19. Li L, Garzione CN (2017) Spatial distribution and controlling factors of stable isotopes in meteoric waters on the Tibetan Plateau: Implications for paleoelevation reconstruction. Earth Planet Sci Lett 460,
302-14.

20. Xu YW, Kang SC, Zhang YL, Zhang YJ (2011) A method for estimating the contribution of evaporative vapor from Nam Co to local atmospheric vapor based on stable isotopes of water bodies. Chin Sci Bull 56, 1511-7.

21. Bershaw J, Penny SM, Garzione CN (2012) Stable isotopes of modern water across the Himalaya and eastern Tibetan Plateau: Implications for estimates of paleoelevation and paleoclimate. $J$ Geophys Res Atmos 117, D02110.

22. Liu ZF (2008) Study on stable isotope in hydrological processes in Naqu River basin of the central Tibetan Plateau. PhD thesis, Graduate University of Chinese Academy of Sciences, Beijing.

23. Zhou SQ, Nakawo M, Hashimoto S, Sakai A (2008) The effect of refreezing on the isotopic composition of melting snowpack. Hydrol Process 22, 873-82.

24. Gonfiantini R (1986) Environmental isotopes in lake studies. In: Fritz P, Fontes JC (eds) Handbook of Environmental Isotope Geochemistry the Terrestrial Environment B, Elsevier, New York, pp 113-68.

25. Liu Q, Wang JL, Tian LD, Zang YL (2015) Characteristic of spatial variation in stable isotope in river water across the Qinghai-Tibetan Plateau before the monsoon. J Southwest Univ (Nat Sci) 37(6), 131-6.

26. Liu YH, Fan NJ, An SP, Bai XH, Liu FD, Xu Z, Wang ZS, Liu SR (2008) Characteristics of water isotopes and hydrograph separation during the wet season in the Heishui River, China. J Hydrol 353, 314-21.

27. Ren W, Yao TD, Xie SY (2017) Key drivers controlling the stable isotopes in precipitation on the leeward side of the central Himalayas. Atmos Res 189, 134-40.

28. Gonfiantini R, Roche MA, Olivry JC, Fontes JC, Zuppi GM (2001) The altitude effect on the isotopic composition of tropical rains. Chem Geol 181, 147-67.

29. Peng H, Mayer B, Harris S, Krouse HR (2007) The influence of below-cloud secondary effects on the stable isotope composition of hydrogen and oxygen in precipitation at Calgary, Alberta, Canada. Tellus $B$ Chem Phys Meteorol 59, 698-704.

30. Petit JR, White JWC, Young NW, Jouzel J, Korotkevich YS (1991) Deuterium excess in recent Antarctic snow. $J$ Geophys Res 96, 5113-22.

31. Tian LD, Yao TD, Numaguti A, Sun WZ (2001) Stable isotope variations in monsoon precipitation on the Tibetan Plateau. J Meteor Soc Japan 79, 959-66.

32. Yu WS, Yao TD, Tian LD, Ma YM, Wen R, Devkota L P, Wang WC, Qu DM, et al (2016) Short-term variability in the dates of the Indian monsoon onset and retreat on the southern and northern slopes of the central Himalayas as determined by precipitation stable isotopes. Clim Dyn 47, 159-72.

33. Tian LD, Yao TD, Wen R, Weng YP, Zhao ZP, Qu DM (2012) A primary recognition on the climatic significance of ice core isotope record in Naimona'nyi 
of west Tibetan Plateau. Quat Sci 32, 46-52. [in Chinese]

34. Yao TD, Ding LF, Pu JC, Yutaka A, Tetsuo O, Liu JS, Yang ZH (1991) The $\delta^{18} \mathrm{O}$ features in the snow fall and its relationship with the sources of the water vapor in the Tanggula Mountains regions in Tibetan Plateau. Chin Sci Bull 36, 1570-3.

35. Yang MX, Yao TD, Wang HJ, Tian LD, Gou XH (2006) Estimating the criterion for determining water vapour sources of summer precipitation on the northern Tibetan Plateau. Hydrol Process 20, 505-13.

36. Ren W, Yao TD, Xie SY, He Y (2016) Controls on the stable isotopes in precipitation and surface waters across the southeastern Tibetan Plateau. $J$ Hydrol 545, 276-87.

37. Hren MT, Bookhagen B, Blisniuk PM, Booth AL, Chamberlain CP (2009) $\delta^{18} \mathrm{O}$ and $\delta \mathrm{D}$ of streamwaters across the Himalaya and Tibetan Plateau: Implications for moisture sources and paleoelevation reconstructions. Earth Planet Sci Lett 288, 20-32.

38. Tian LD, Yao TD, Yu WS, Zhang XP, Pu JC (2006) Stable isotopes of precipitation and ice core on the Tibetan Plateau and moisture transports. Quaternary Sciences 26, 145-52. [in Chinese]

39. Jasechko S, Kirchner JW, Welker JM, McDonnell JJ (2016) Substantial proportion of global streamflow less than three months old. Nat Geosci 9, 126-9. 